\title{
Novel risk scoring system for predicting acute respiratory distress syndrome among hospitalized patients with coronavirus disease 2019 in Wuhan, China
}

Mengyuan Liang ${ }^{1 \dagger}$, Miao He ${ }^{1 \dagger}$, Jian Tang ${ }^{1 \dagger}$, Xinliang He ${ }^{1 \dagger}$, Zhijun Liu ${ }^{2}$, Siwei Feng ${ }^{1}$, Ping Chen ${ }^{1}$, Hui Li ${ }^{1}$, Yu'e Xue , Tao Bai ${ }^{3}$, Yanling $\mathrm{Ma}^{1 *}$ and Jianchu Zhang ${ }^{1 *}$

\begin{abstract}
Background: The mortality rate from acute respiratory distress syndrome (ARDS) is high among hospitalized patients with coronavirus disease 2019 (COVID-19). Hence, risk evaluation tools are required to immediately identify high-risk patients upon admission for early intervention.

Methods: A cohort of 220 consecutive patients with COVID-19 were included in this study. To analyze the risk factors of ARDS, data obtained from approximately $70 \%$ of the participants were randomly selected and used as training dataset to establish a logistic regression model. Meanwhile, data obtained from the remaining $30 \%$ of the participants were used as test dataset to validate the effect of the model.

Results: Lactate dehydrogenase, blood urea nitrogen, D-dimer, procalcitonin, and ferritin levels were included in the risk score system and were assigned a score of $25,15,34,20$, and 24 , respectively. The cutoff value for the total score was $>35$, with a sensitivity of $100.00 \%$ and specificity of $81.20 \%$. The area under the receiver operating characteristic curve and the Hosmer-Lemeshow test were 0.967 (95\% confidence interval [CI]: 0.925-0.989) and 0.437 ( $P$ Value $=0.437$ ). The model had excellent discrimination and calibration during internal validation.
\end{abstract}

Conclusions: The novel risk score may be a valuable risk evaluation tool for screening patients with COVID-19 who are at high risk of ARDS.

Keywords: COVID-19, ARDS, Risk score

\footnotetext{
* Correspondence: mayanling811@hust.edu.cn; zsn0928@163.com

${ }^{\dagger}$ Mengyuan Liang, Miao He, Jian Tang and Xinliang He contributed equally

to this work.

1 Department of Respiratory and Critical Care Medicine, Union Hospital,

Tongji Medical Collage, Huazhong University of Science and Technology,

1277 Jiefang Avenue, Wuhan 430022, Hubei Province, China

Full list of author information is available at the end of the article
}

C C The Author(s). 2020 Open Access This article is licensed under a Creative Commons Attribution 4.0 International License, which permits use, sharing, adaptation, distribution and reproduction in any medium or format, as long as you give appropriate credit to the original author(s) and the source, provide a link to the Creative Commons licence, and indicate if changes were made. The images or other third party material in this article are included in the article's Creative Commons. licence, unless indicated otherwise in a credit line to the material. If material is not included in the article's Creative Commons licence and your intended use is not permitted by statutory regulation or exceeds the permitted use, you will need to obtain permission directly from the copyright holder. To view a copy of this licence, visit http://creativecommons.org/licenses/by/4.0/. The Creative Commons Public Domain Dedication waiver (http://creativecommons.org/publicdomain/zero/1.0/) applies to the data made available in this article, unless otherwise stated in a credit line to the data. 


\section{Background}

In late December 2019, an outbreak of pneumonia of unknown etiology first occurred inWuhan, China, and rapidly spread worldwide [1, 2]. Later studies confirmed that the disease was caused by a novel coronavirus referred to as severe acute respiratory syndrome coronavirus 2 (SARS-CoV- 2) [3, 4]. Then, in February 2020 , this emerging infectious disease was officially named as coronavirus disease 2019 (COVID-19) by the World Health Organization (WHO) [5, 6]. Although most patients diagnosed with COVID-19 experience mild symptoms, 19\% could develop severe or fatal symptoms and present with intractable conditions, particularly ARDS [7]. With respect to its definition, the pathogenesis of ARDS involves rapidly progressing respiratory failure from non-cardiogenic pulmonary edema, which may require mechanical ventilation due to severe hypoxia and difficulty in breathing [8]. Currently, the Berlin definition for ARDS is utilized, and it recommends the use of three categories to differentiate severity based on partial pressure of oxygen $(\mathrm{PaO} 2) /$ initial fraction of inspired oxygen (FiO2) [9]. According to a recently published study, the mortality rate of patients with COVID-19 who present with ARDS is > $70 \%$ [10]. Moreover, the current guidelines for the treatment of ARDS focus on lung-protective ventilation and fluid conservative management, and early interventions were found to have a better therapeutic effect [11]. Thus, to facilitate the early identification of high-risk patients and prevent the development of or reduce the severity of ARDS, the predictors of this condition must be determined. Recent studies have identified several predictors for the unfavorable outcomes of COVID-19 [12-14]. However, only few predictors of the onset of ARDS were determined. Thus, the key indicators for the risk of ARDS should be immediately identified upon admission. Moreover, risk evaluation models that use a combination of risk factors are likely to increase the power of prediction. Some risk scoring systems have been developed for several clinical conditions, including coronary heart disease [15], heart failure [16], and stroke [17], and these systems were found to have great practical value. Thus, a systemic evaluation tool involving risk scores, which can be practical for clinicians, is urgently needed. In this study, we obtained data from 220 patients with confirmed COVID-19 who died in or were discharged from the isolation ward of the Department of Respiratory and Critical Care Medicine at Wuhan Union Hospital between January 10, 2020, and March 5, 2020. The current study aimed to explore the risk factors associated with ARDS in patients with COVID19 and develop a risk evaluation system for predicting ARDS.

\section{Methods}

\section{Study design and data collection}

This was a retrospective, observational cohort study performed at the isolation ward of the Department of Respiratory and Critical Care Medicine, Wuhan Union Hospital (Huazhong University of Science and Technology, Wuhan, China). We included all adult patients who were diagnosed with COVID-19, according to the WHO interim guidance, and who were discharged or died between January 10, 2020, and March 5, 2020. Since Wuhan Union Hospital has been a designated hospital for treating patients with COVID-19 since January 10, 2020, the population constituted a representative sample of all patients with COVID-19 seeking treatment. This study was approved by the research ethics commission of Wuhan Union Hospital (KY-2020-0040), and the need for informed consent was waived. Demographic, clinical, laboratory, and imaging data were extracted from the electronic medical record system of Wuhan Union Hospital through a standardized data collection form. All data were checked by two physicians (YM and JT), and a third researcher $(\mathrm{MH})$ reviewed and made corrections to any differences in data.

\section{Case definition}

COVID-19 was confirmed based on the examination of respiratory specimens using real-time reverse transcription polymerase chain reaction (RT-PCR). The examination was performed at the clinical laboratory of Wuhan Union Hospital, which is a qualified institution for nucleic acid testing. Patients who were discharged met all of the following criteria: 1) absence of fever for at least 3 days, 2) notable improvement of findings on chest computed tomography (CT) scan, 3) remission of respiratory symptoms, and 4) two continuous negative results of SARS-CoV-2 RNA using throat swab samples collected at least $24 \mathrm{~h}$ apart.

Fever was defined as an axillary temperature of at least $37.3^{\circ} \mathrm{C}$. ARDS was diagnosed according to the Berlin Definition [9]. In brief, patients who experienced acute respiratory failure not fully explained by cardiac failure or fluid overload, with $\mathrm{PaO} 2 / \mathrm{FiO} 2 \leq 300 \mathrm{mmHg}$ and positive end expiratory pressure or continuous positive airway pressure $\geq 5 \mathrm{~cm} \mathrm{H} 2 \mathrm{O}$, and who present with bilateral opacities on chest radiography not fully explained by effusions, lobar or lung collapse, or nodules are diagnosed with ARDS $[8,9]$.

\section{Clinical examinations and treatments}

Routine blood examinations, including complete blood count, liver function, blood lipids, fasting blood glucose, kidney function, uric acid, lactate dehydrogenase, creatine kinase, and assessment of myocardial enzymes, coagulation profile, serum C-reactive protein (CRP) level, 
erythrocyte sedimentation rate (ESR), serum procalcitonin (PCT) level, and ferritin level, were performed upon patient admission, and re-examination was conducted at least once every 3 days during hospitalization. All patients who were admitted underwent chest CT scans.

Patients admitted to the isolation ward received standard treatment according to the Chinese management guidelines for COVID-19 (version 6.0) [18]. In brief, the antiviral treatment included interferon alpha inhalation (50 $\mu \mathrm{g}$ twice daily), lopinavir, and ritonavir (400 and 100 $\mathrm{mg}$ twice daily, respectively), and arbidol (200 mg twice daily). Treatment with corticosteroid ( $40-80 \mathrm{mg} /$ day) and gamma globulin (15-20 g/day) was initiated if patients presented with a resting respiratory rate $>30$ per min, oxygen saturation $<93 \%$ but without the need for supplemental oxygen, or chest radiography showing $>50 \%$ progression within $48 \mathrm{~h}$. Oral and intravenous antibiotics were administered if there was a high risk of concomitant bacterial infection.

\section{Statistical methods}

Data obtained from approximately $70 \%$ of the participants $(n=154)$ were randomly selected and used as training dataset to establish a logistic regression model. Meanwhile, data obtained from the remaining 30\% of the patients $(n=66)$ were used as test dataset to validate the effect of the model. Using the training dataset, continuous and categorical variables were presented as median with interquartile range (IQR) and total number (n) with percentage (\%), respectively. The Mann-Whitney U test, $\mathrm{X} 2$ test, and Fisher's exact test were used accordingly to compare the differences between patients with and without ARDS. Univariate and multivariate logistic regression models were used to test the association between the risk factors and onset of ARDS. A receiver operating characteristic (ROC) curve was established to depict the predictive ability of the variables. The Youden index, which was calculated as the sum of the sensitivity and specificity minus 1 , was used to determine the optimal cutoff value. The area under the curve (AUC) was calculated with the ROC curves to determine the differentiating abilities of the corresponding risk factors. Variables with significant differences between patients with and without ARDS were included in the multivariate logistic regression analysis, and a stepwise selection method was used to identify the variables included in the predictive model. The assigned risk score for the corresponding variables was determined by multiplying the $\beta$ coefficients of significant variables by 10 and rounding off the value to the nearest integers, and the total risk score was calculated as the sum of those of the individual risk factors. In the verification dataset, the model was evaluated using the Hosmer-Lemeshow test and ROC curve. All data analyses were performed using
SAS version 9.4 (SAS Institute Inc., Cary, NC, the USA). Two-tailed $P$ values $<0.05$ for all tests were considered statistically significant. $P$ values $<0.1$ were used as the selection criteria for variables in the model.

\section{Results}

Of the 154 COVID-19 patients whose data were used to establish the model, 37 (24.03\%)developed ARDS during hospitalization. Data about the characteristics of the study population collected upon admission and grouped according to the diagnosis of ARDS are presented in Table 1.

The median age of the patients was 57.5 (range: 2196, IQR: 45-75) years. The median age of the ARDS group was significantly higher than that of the nonARDS group (69 [IQR: $62-74$ ] vs 54 years [IQR 41-65] years). Approximately $53.90 \%$ of the patients were men. The male patients accounted for a larger proportion in the ARDS group (70.27\%) than in the non-ARDS group (48.72\%). About $13.64 \%$ of the patients were smokers, and the proportion of smokers was larger in the ARDS group (24.32\%) than in the non-ARDS group (10.26\%). The patients in the ARDS and non-ARDS groups did not differ significantly in terms of weight and clinical features upon admission. With respect to clinical features, fever was the most common symptom upon admission that was observed in $89.61 \%$ of the total population. The median time from symptoms onset to hospitalization in the ARDS group and non-ARDS group was 8 days and 10 days, respectively and there was no statistical difference. Moreover, patients with comorbidities were more likely to develop ARDS than patients without comorbidities $(72.97 \%$ vs. $35.04 \%)$. The comorbidities included hypertension (43.24\% vs $23.08 \%$ ), diabetes $(35.14 \%$ vs. $12.82 \%)$, coronary heart disease (CHD, $16.22 \%$ vs. $6.84 \%)$, and malignancies ( $10.81 \%$ vs. $1.71 \%)$. However, the difference was not significant in terms of the prevalence of CHD.

In terms of the results of the laboratory examinations performed upon admission, COVID-19 patients with ARDS had significantly higher levels of white blood cell (WBC: $6.50 \times 109$ /L, IQR: $4.79-10.26$ vs. $4.64 \times 109 / \mathrm{L}$, IQR: $3.50-6.00$ ), alanine transaminase (ALT: $44 \mathrm{U} / \mathrm{L}$, IQR: $31-65$ vs. $28 \mathrm{U} / \mathrm{L}$, IQR: $18-48)$, aspartate aminotransferase (AST: $48 \mathrm{U} / \mathrm{L}, \mathrm{IQR}: 37-79$ vs. $30 \mathrm{U} / \mathrm{L}$, IQR: 23-41), lactate dehydrogenase (LDH: $415 \mathrm{U} / \mathrm{L}$, IQR: 307-594 vs. $233.5 \mathrm{U} / \mathrm{L}, \mathrm{IQR}:$ 185-291.5), creatinine (74.5 $\mu \mathrm{mol} / \mathrm{L}$, IQR: $65.5-103.6$ vs. $66.9 \mu \mathrm{mol} / \mathrm{L}$, IQR: 56.3-78.7), blood urea nitrogen (BUN: $5.91 \mathrm{mmol} / \mathrm{L}$, IQR: $4.50-10.90$ vs. $4.00 \mathrm{mmol} / \mathrm{L}$, IQR: $3.13-4.93)$, creatine kinase-MB (CK-MB: $1.05 \mathrm{ng} / \mathrm{mL}$, IQR: $0.8-2.4$ vs. $0.5 \mathrm{ng} / \mathrm{mL}$, IQR: $0.3-0.9)$, highly sensitive troponin I (14.15 ng/L, IQR: $8.0-39.6$ vs. $3.65 \mathrm{ng} / \mathrm{L}$, IQR: $1.9-8.6$ ), prothrombin time (PT: $13.9 \mathrm{~s}$, IQR: $13.1-14.7$ vs. $13.3 \mathrm{~s}$, 
Table 1 Characteristics of the study population

\begin{tabular}{|c|c|c|c|c|}
\hline & Total, $(n=154)$ & ARDS, $(n=37)$ & Non-ARDS, $(n=117)$ & $P$ value \\
\hline \multicolumn{5}{|l|}{ Demographics and clinical characteristics } \\
\hline Age (years) & $57.5(45-70)$ & $69(62-74)$ & $54(41-65)$ & $<0.001^{* * *}$ \\
\hline \multicolumn{5}{|l|}{ Gender, n (\%) } \\
\hline Male & $83(53.90 \%)$ & $26(70.27 \%)$ & $57(48.72 \%)$ & $0.022^{*}$ \\
\hline Female & $71(46.10 \%)$ & $11(29.73 \%)$ & $60(51.28 \%)$ & \\
\hline Smoking habits, $\mathrm{n}(\%)$ & $13(13.64 \%)$ & $9(24.32 \%)$ & $12(10.26 \%)$ & $0.030^{*}$ \\
\hline Weight (kg) & $65.0(55.0-75.0)$ & $63.5(55.0-73.0)$ & $65.0(55.5-82.0)$ & 0.511 \\
\hline Fever, n (\%) & $138(89.61 \%)$ & $34(91.89 \%)$ & $104(88.89 \%)$ & 0.832 \\
\hline Cough, n (\%) & $102(66.23 \%)$ & $21(56.76 \%)$ & $81(69.23 \%)$ & 0.162 \\
\hline Diarrhea, n (\%) & $17(11.04 \%)$ & $4(10.81 \%)$ & $13(11.11 \%)$ & 0.959 \\
\hline Fatigue, n (\%) & $109(70.78 \%)$ & $28(75.68 \%)$ & $81(69.23 \%)$ & 0.452 \\
\hline Dyspnea, n (\%) & $62(40.26 \%)$ & $14(37.84 \%)$ & $48(41.03 \%)$ & 0.730 \\
\hline Time from symptoms onset to hospitalization, $d$ & $10(6-13)$ & $8(6-11)$ & $10(6-15)$ & 0.059 \\
\hline Comorbidity, n (\%) & $68(44.16 \%)$ & 27 (72.97\%) & 41 (35.04\%) & $<0.001^{* * *}$ \\
\hline Hypertension, n (\%) & $43(27.92 \%)$ & $16(43.24 \%)$ & $27(23.08 \%)$ & $0.017^{*}$ \\
\hline Diabetes, n (\%) & $28(18.18 \%)$ & $13(35.14 \%)$ & $15(12.82 \%)$ & $0.002^{* *}$ \\
\hline CHD, n (\%) & $14(9.09 \%)$ & $6(16.22 \%)$ & $8(6.84 \%)$ & 0.161 \\
\hline Malignancy, n (\%) & $6(3.09 \%)$ & $4(10.81 \%)$ & $2(1.71 \%)$ & $0.045^{*}$ \\
\hline \multicolumn{5}{|l|}{ Laboratory findings } \\
\hline White blood cell $\left(\times 10^{9} / \mathrm{L}\right)$ & $4.845(3.71-6.52)$ & $6.50(4.79-10.26)$ & $4.64(3.50-6.00)$ & $<0.001^{* * *}$ \\
\hline Lymphocyte $\left(\times 10^{9} / \mathrm{L}\right)$ & $0.975(0.67-1.38)$ & $0.53(0.40-1.07)$ & $1.03(0.78-1.52)$ & $<0.001^{* * *}$ \\
\hline Hemoglobin(g/L) & $126(115-137)$ & $129(119-144)$ & $126(114-137)$ & 0.136 \\
\hline ALT (U/L) & $33.5(19-54)$ & $44(31-65)$ & $28(18-48)$ & $0.002^{* *}$ \\
\hline AST (U/L) & $34(25-47)$ & $48(37-79)$ & $30(23-41)$ & $<0.001^{* * *}$ \\
\hline LDH (U/L) & $262(198-353)$ & $415(307-594)$ & $233.5(185-291.5)$ & $<0.001^{* * *}$ \\
\hline Albumin (g/L) & $32.35(28.9-35.80)$ & $29.4(26.5-33.0)$ & $33.7(29.9-36.5)$ & $<0.001^{* * *}$ \\
\hline Creatinine $(\mu \mathrm{mol} / \mathrm{L})$ & $69.4(58.4-83.6)$ & $74.5(65.5-103.6)$ & $66.9(56.3-78.7)$ & $0.004^{* *}$ \\
\hline Blood urea nitrogen $(\mathrm{mmol} / \mathrm{L})$ & $4.25(3.30-5.91)$ & $5.91(4.50-10.90)$ & $4.00(3.13-4.93)$ & $<0.001^{* * *}$ \\
\hline CK-MB (ng/mL) & $0.6(0.4-1.1)$ & $1.05(0.8-2.4)$ & $0.5(0.3-0.9)$ & $<0.001^{* * *}$ \\
\hline Troponin I (ng/L) & $5.0(2.3-11.9)$ & $14.15(8.0-39.6)$ & $3.65(1.9-8.6)$ & $<0.001^{* * *}$ \\
\hline Prothrombin time (s) & $13.4(12.8-14.2)$ & $13.9(13.1-14.7)$ & $13.3(12.75-14.1)$ & $0.033^{*}$ \\
\hline D-Dimer $(\mu \mathrm{g} / \mathrm{ml})$ & $0.50(0.31-1.58)$ & $1.88(0.62-8.00)$ & $0.465(0.24-0.945)$ & $<0.001^{* * *}$ \\
\hline C-Reactive protein (mg/L) & $23.395(4.675-59.565)$ & $61.69(41.63-104.38)$ & $9.58(2.71-37.20)$ & $<0.001^{* * *}$ \\
\hline $\operatorname{ESR}(\mathrm{mm} / \mathrm{h})$ & $48.5(29-73)$ & $64.0(38.5-73.5)$ & $45.5(25-70.5)$ & $0.046^{*}$ \\
\hline Procalcitonin $(\mathrm{ng} / \mathrm{ml})$ & $0.09(0.05-0.21)$ & $0.26(0.14-0.63)$ & $0.07(0.04-0.12)$ & $<0.001^{* * *}$ \\
\hline Ferritin (ng/ml) & $509.32(226.86-937.73)$ & $1305.325(664.355-2000.00)$ & $416.72(190.165-692.415)$ & $<0.001^{* * *}$ \\
\hline \multicolumn{5}{|l|}{ Imaging features } \\
\hline Consolidation, n (\%) & $48(31.17 \%)$ & $9(24.32 \%)$ & 39 (33.33\%) & 0.302 \\
\hline Bilateral infiltration, $\mathrm{n}(\%)$ & $144(93.51 \%)$ & 34 (91.89\%) & 110 (94.02\%) & 0.941 \\
\hline \multicolumn{5}{|l|}{ Outcome } \\
\hline Death & 16 (10.39\%) & 15 (40.54\%) & $1(0.85 \%)$ & $<0.001^{* * *}$ \\
\hline
\end{tabular}

Mann-Whitney $\mathrm{U}$ tests were used to detect differences of continuous variables between ARDS and non-ARDS group. Chi-squared tests or Fisher's exact tests were used to detect difference of categorical variables between ARDS and non-ARDS group ${ }^{*} p$-value $<0.05$

${ }^{*} p$-value $<0.01$

*** $p$-value $<0.001$ 
IQR: $12.75-14.1)$, D-dimer $(1.88 \mu \mathrm{g} / \mathrm{mL}$, IQR: 0.62-8.00 vs. $0.465 \mu \mathrm{g} / \mathrm{mL}$, IQR: $0.24-0.945)$, CRP $(61.69 \mathrm{mg} / \mathrm{L}$, IQR: $41.63-104.38$ vs. $9.58 \mathrm{mg} / \mathrm{L}, \mathrm{IQR}: 2.71-37.20)$, ESR (64.0 mm/h, IQR: $38.5-73.5$, vs. $9.58 \mathrm{~mm} / \mathrm{h}, \mathrm{IQR}: 25-$ 70.5), PCT (0.26 ng/mL, IQR: $0.14-0.63$ vs. $0.07 \mathrm{ng} / \mathrm{mL}$, I-QR: $0.04-0.12)$, and ferritin (1305.325 ng/mL, IQR: 664.355-2000.00 vs. $416.72 \mathrm{ng} / \mathrm{mL}$, IQR: $190.165-$ 692.415) than COVID-19 patients without ARDS. Moreover, COVID-19 patients with ARDS had lower levels of lymphocytes $(0.53 \times 109$ /L, IQR: $0.40-1.07$ vs $1.03 \times 109$ /L, IQR: 0.78-1.52) and serum albumin (ALB: $29.4 \mathrm{~g} / \mathrm{L}$, IQR: $26.5-33.0$ vs $33.7 \mathrm{~g} / \mathrm{L}$, IQR: 29.9-36.5) than COVID-19 patients without ARDS. However, there was no significant difference between the ARDS and nonARDS groups in terms of consolidation and bilateral pulmonary infiltration on chest CT scans.

Regarding other important indicators such as $\mathrm{PaO} 2$ and $\mathrm{PaO} 2 / \mathrm{FiO} 2$ at admission, We only recorded the above indicators for 29 patients, of which 28 patients were ARDS patients and 1 was non-ARDS patient. The median $\mathrm{PaO} 2$ of ARDS patients is $64 \mathrm{mmHg}, \mathrm{PaO} 2 / \mathrm{FiO} 2$ is $101 \mathrm{mmHg}$.the Non-ARDS patient is $81 \mathrm{mmHg}$ and $245 \mathrm{mmHg}$, respectively. Although the ARDS group has worse indicators, the data is insufficient, resulting in data differences between the two groups that are not comparable.

The mortality in the ARDS group was 40.54\%, while the mortality in the non-ARDS group was much lower than that of the ARDS group, which was $0.85 \%$. This indicates that the ARDS group has a higher risk of death, and also shows the importance of the risk assessment model, which provides a basis for early detection and early treatment.

Table 2 shows the predictive efficiency of continuous variables that were differentially distributed between the ARDS and non-ARDS groups. The cutoff criteria were selected with the best Youden indices, and the associated sensitivities, specificities, positive likelihood ratios (+LR), and negative likelihood ratios (-LR) were also presented. The AUC values were determined using the ROC curves, as shown in Figure S1. Among the continuous risk factors, ferritin level had the best differentiating ability, with an AUC of 0.872 , and the associated cutoff value was $>950 \mathrm{ng} / \mathrm{mL}$.

The results for the association between differentially distributed risk factors and the risk of ARDS are shown in Table 3. The unadjusted models were first used to analyze the risk of individual variables. Then, the multivariate logistic regression model was fitted with a stepwise selection method, and LDH, BUN, D-dimer, PCT, and ferritin levels were selected and used in the combined prediction model. Specifically, COVID-19 patients with $\mathrm{LDH}$ values $\geq 295 \mathrm{U} / \mathrm{L}$ were assigned a score of 25 ; those with $\mathrm{BUN}$ values $>5.12 \mathrm{mmol} / \mathrm{L}$, a score of
15; D-dimer values $\geq 5.00 \mu \mathrm{g} / \mathrm{mL}$, a score of 34 ; PCT values $>0.11 \mathrm{ng} / \mathrm{mL}$, a score of 20 ; and serum ferritin values $\geq 950 \mathrm{ng} / \mathrm{mL}$, a score of 24 . The total risk scores were calculated as the sum of the scores of the individual risk factors. The ROC curves of the total risk score for predicting ARDS are depicted in Fig. 1, and the associated sensitivities, specificities, +LRs, and -LRs of each cutoff point are presented in Table S1. In the current study cohort, the optimal cutoff value of the ARDS risk score was $>35$, with a sensitivity of $100 \%$ and a specificity of $81.20 \%$. The AUC of the ARDS score based on the ROC curve was 0.967 (95\% CI: 0.925-0.989).

In this study, data obtained from the remaining $30 \%$ of the patients were used as validation dataset, In total, 17 of 66 patients had ARDS. The sensitivity of the model was $71.43 \%$ and specificity was $78.85 \%$. The AUC of the test sample model was 0.819 (95\% CI: 0.680-0.959). The $P$ value for the Hosmer-Lemeshow test was 0.312 , indicating that the model had a good fit (Table 4).

\section{Discussion}

This is a retrospective study of patients diagnosed with COVID-19 and admitted to Wuhan Union Hospital. By comparing patients with and without ARDS, a panel of risk factors were identified. The univariate logistic regression model was used to assess the risk of individual factors, and the multivariate logistic regression model was utilized to identify the factors for the risk prediction model, which include LDH, BUN, D-dimer, PCT, and serum ferritin levels. Moreover, by assigning a risk score for the significant factors and calculating the total risk score, COVID-19 patients with a high risk of ARDS during hospitalization could be identified and this risk evaluation system had a good predictive efficiency.

Among the variables included in the prediction model, the D-dimer level was assigned with the largest risk score at 34. Although the underlying mechanism of COVID-19 is still unknown, patients with this condition have an increased risk of thrombosis (preliminary data not shown). Bronchoscopy showed red jelly-like sputum, and biopsy of the lung tissues revealed disseminated hemorrhage in the pulmonary alveoli and clot formation within the microvessels $[19,20]$. This result emphasizes the role of blood clotting dysfunction, as indicated by elevated D-dimer levels. Intra-alveoli hemorrhage and intravascular thrombosis are bound to reduce gas exchange function, and this leads to severe hypoxia, which is considered a key manifestation of ARDS [8].

In previous studies, an elevated ferritin level was considered a risk factor for the severity of different types of infection [21-23]. Although several studies have compared the difference in risk factors between patients with favorable and unfavorable outcomes, sufficient attention has not been paid to ferritin levels $[10,13,24]$. One 
Table 2 Predictive efficiency of continuous risk factors for developing ARDS

\begin{tabular}{|c|c|c|c|c|c|c|c|}
\hline Variables & Youden Index & Cut-off criterion & Sensitivity & Specificity & $+\mathrm{LR}$ & $-\mathrm{LR}$ & AUC $(95 \% \mathrm{Cl})$ \\
\hline Age (years) & 0.419 & $\geq 65$ & $67.57 \%$ & $74.36 \%$ & 2.64 & 0.44 & $0.725(0.647-0.793)$ \\
\hline White blood cell $\left(\times 10^{9} / \mathrm{L}\right)$ & 0.363 & $>6.10$ & $59.46 \%$ & $76.92 \%$ & 2.58 & 0.53 & $0.714(0.635-0.783)$ \\
\hline Lymphocyte $\left(\times 10^{9} / \mathrm{L}\right)$ & 0.496 & $\leq 0.71$ & $67.57 \%$ & $82.05 \%$ & 3.76 & 0.40 & $0.766(0.691-0.830)$ \\
\hline $\operatorname{ALT}(\mathrm{U} / \mathrm{L})$ & 0.332 & $\geq 30$ & $81.08 \%$ & $52.14 \%$ & 1.69 & 0.36 & $0.676(0.596-0.749)$ \\
\hline AST (U/L) & 0.423 & $\geq 37$ & $75.68 \%$ & $66.67 \%$ & 2.27 & 0.36 & $0.772(0.697-0.835)$ \\
\hline $\mathrm{LDH}(\mathrm{U} / \mathrm{L})$ & 0.597 & $\geq 295.0$ & $83.78 \%$ & $75.86 \%$ & 3.47 & 0.21 & $0.860(0.795-0.911)$ \\
\hline Albumin (g/L) & 0.304 & $<28.5$ & $43.24 \%$ & $87.18 \%$ & 3.37 & 0.65 & $0.685(0.605-0.757)$ \\
\hline Creatinine $(\mu \mathrm{mol} / \mathrm{L})$ & 0.340 & $\geq 88.0$ & $45.95 \%$ & $88.03 \%$ & 3.84 & 0.61 & $0.659(0.579-0.734)$ \\
\hline BUN (mmol/L) & 0.479 & $>5.12$ & $67.57 \%$ & $80.34 \%$ & 3.44 & 0.40 & $0.763(0.688-0.828)$ \\
\hline CK-MB (ng/mL) & 0.498 & $>0.70$ & $77.78 \%$ & $72.00 \%$ & 2.78 & 0.31 & $0.803(0.726-0.866)$ \\
\hline Troponin I (ng/L) & 0.507 & $>4.70$ & $88.89 \%$ & $61.76 \%$ & 2.32 & 0.18 & $0.821(0.746-0.881)$ \\
\hline Prothrombin time (s) & 0.209 & $>14.20$ & $37.84 \%$ & $83.04 \%$ & 2.23 & 0.75 & $0.618(0.535-0.697)$ \\
\hline D-Dimer ( $\mu \mathrm{g} / \mathrm{ml})$ & 0.307 & $\geq 5.00$ & $32.43 \%$ & $98.21 \%$ & 18.16 & 0.69 & $0.691(0.611-0.764)$ \\
\hline C-Reactive protein (mg/L) & 0.639 & $\geq 38.00$ & $86.49 \%$ & $77.39 \%$ & 3.83 & 0.17 & $0.852(0.785-0.904)$ \\
\hline $\mathrm{ESR}(\mathrm{mm} / \mathrm{h})$ & 0.294 & $\geq 60.0$ & $63.89 \%$ & $65.52 \%$ & 1.85 & 0.55 & $0.611(0.529-0.689)$ \\
\hline Procalcitonin (ng/ml) & 0.581 & $>0.11$ & $83.78 \%$ & $74.31 \%$ & 3.26 & 0.22 & $0.854(0.787-0.907)$ \\
\hline Ferritin (ng/ml) & 0.602 & $\geq 950.00$ & $69.44 \%$ & $90.74 \%$ & 7.50 & 0.34 & $0.872(0.806-0.921)$ \\
\hline
\end{tabular}

${ }^{*} p$-value $<0.05$

${ }^{* *} p$-value $<0.01$

${ }^{* * *} p$-value $<0.001$

recent study reported that the non-survivors of COVID19 had higher serum ferritin levels than survivors [25]. By contrast, the formation of toxic hydroxyl radicals from superoxide anions and hydrogen peroxide requires free iron, the storage of which correlates with that of ferritin. In contrast, proinflammatory cytokines, including interleukin-1 $\beta$ (IL-1 $\beta$ ), interleukine-6 (IL-6), and tumor necrosis factor- $\alpha$, can directly increase the synthesis of ferritin [26].

ARDS is characterized by acute, diffuse, inflammatory lung injury; and inflammatory markers, including CRP, ESR, PCT, and serum ferritin, may worsen the clinical symptoms [27, 28]. In addition to serum ferritin, PCT was included in the prediction model. Although ferritin is considered a marker of tissue inflammation, PCT is more commonly considered as an indicator of bacterial infection $[29,30]$. This result indicates that concomitant bacterial infection may play an important role in the progression of ARDS among patients with COVID-19, and this finding is in accordance with a previous hypothesis on the pathogenesis of the disease [31-33]. Thus, for high-risk patients with elevated PCT levels, treatment with antibiotics may be effective in preventing ARDS. Although we have not obtained precise etiological evidence, we found that the Procalcitonin in the ARDS group was higher and exceeded the normal range, accompanied by an increase in White blood cell count, C-Reactive protein, ESR, Ferritin and a decrease in lymphocyte count. This also suggests that it seems that patients in the ARDS group have worse immunity and a higher risk of bacterial/fungal co-infection.

Since SARS-CoV2 attack pulmonary epithelial cells and there is a risk of bacterial infection, the release of intracellular LDH, which is considered a general index of cell injury, is bound to increase [34, 35]. Moreover, recent studies have revealed that lactate may suppress the function of immune cells, and LDH can be an indicator of immunosuppression [36, 37]. Thus, special attention must be paid to this finding, as the current research and previous reports $[10,25]$ have shown that a decreased number of lymphocytes can be associated with unfavorable outcomes among patients with COVID-19. This result indicated that immune suppression had an important role in disease prognosis. However, in our model, the addition of lymphocytes does not improve the predictive efficiency of the model, indicating that the effect of lymphocytes on ARDS may be explained by other variables, including $\mathrm{LDH}$.

Moreover, the importance of BUN in predicting ARDS has not received special attention. As severe infection and tissue damage can increase the rate of protein degradation [38], patients with ARDS had elevated BUN levels. Moreover, the cutoff value for BUN levels in predicting ARDS is $>5.12 \mathrm{mmol} / \mathrm{L}$, which is still within the normal range. BUN levels higher than the normal range can indicate $>50 \%$ loss of renal function, and this may 
Table 3 Risk factors for developing ARDS among hospitalized COVID-19 patients

\begin{tabular}{|c|c|c|c|c|c|c|}
\hline Variables & Univariable OR $(95 \% \mathrm{Cl})$ & $P$ value & Multivariable OR $(95 \% \mathrm{Cl})$ & $P$ value & $\beta$ coefficients & Assigned risk score \\
\hline \multicolumn{7}{|l|}{ Age (years) } \\
\hline$<65$ & 1 (reference) & $\ldots$ & $\ldots$ & $\ldots$ & $\ldots$ & $\ldots$ \\
\hline$\geq 65$ & $6.041(2.704-13.496)$ & $<0.001^{* * *}$ & $\ldots$ & $\ldots$ & $\ldots$ & $\ldots$ \\
\hline Male (vs female) & $2.488(1.126-5.497)$ & $0.024^{*}$ & $\ldots$ & $\ldots$ & $\ldots$ & $\ldots$ \\
\hline Smoking (vs non-smoker) & $2.813(1.077-7.342)$ & $0.035^{*}$ & $\ldots$ & $\ldots$ & $\ldots$ & $\ldots$ \\
\hline Comorbidity (vs not present) & $5.005(2.207-11.351)$ & $<0.001^{* * *}$ & $\ldots$ & $\ldots$ & $\ldots$ & $\ldots$ \\
\hline Hypertension (vs not present) & $2.540(1.165-5.539)$ & $0.019^{*}$ & $\ldots$ & $\ldots$ & $\ldots$ & $\ldots$ \\
\hline Diabetes (vs not present) & $3.683(1.550-8.752)$ & $0.003^{* *}$ & $\ldots$ & $\ldots$ & $\ldots$ & $\ldots$ \\
\hline CHD (vs not present) & $2.637(0.851-8.173)$ & 0.093 & $\ldots$ & $\ldots$ & $\ldots$ & $\ldots$ \\
\hline Malignancy (vs not present) & $6.966(1.222-39.717)$ & $0.029^{*}$ & $\ldots$ & $\ldots$ & $\ldots$ & $\ldots$ \\
\hline \multicolumn{7}{|l|}{ White blood cell $\left(\times 10^{9} / \mathrm{L}\right)$} \\
\hline$\leq 6.10$ & 1 (reference) & $\ldots$ & $\ldots$ & $\ldots$ & $\ldots$ & $\ldots$ \\
\hline$>6.10$ & $4.889(2.231-10.715)$ & $<0.001^{* * *}$ & $\ldots$ & $\ldots$ & $\ldots$ & $\ldots$ \\
\hline \multicolumn{7}{|l|}{ Lymphocyte $\left(\times 10^{9} / \mathrm{L}\right)$} \\
\hline$>0.71$ & 1 (reference) & $\ldots$ & $\ldots$ & $\ldots$ & $\ldots$ & $\ldots$ \\
\hline$\leq 0.71$ & $9.523(4.133-21.941)$ & $<0.001^{* * *}$ & $\ldots$ & $\ldots$ & $\ldots$ & $\ldots$ \\
\hline \multicolumn{7}{|l|}{$\operatorname{ALT}(\mathrm{U} / \mathrm{L})$} \\
\hline$<30$ & 1 (reference) & $\ldots$ & $\ldots$ & $\ldots$ & $\ldots$ & $\ldots$ \\
\hline$\geq 30$ & 4.667 (1.899-11.469) & $<0.001^{* * *}$ & $\ldots$ & $\ldots$ & $\ldots$ & $\ldots$ \\
\hline \multicolumn{7}{|l|}{ AST (U/L) } \\
\hline$<37$ & 1 (reference) & $\ldots$ & $\ldots$ & $\ldots$ & $\ldots$ & $\ldots$ \\
\hline$\geq 37$ & $6.221(2.676-14.462)$ & $<0.001^{* * *}$ & $\ldots$ & $\ldots$ & $\ldots$ & $\ldots$ \\
\hline \multicolumn{7}{|l|}{$\mathrm{LDH}(\mathrm{U} / \mathrm{L})$} \\
\hline$<295.0$ & 1 (reference) & $\ldots$ & 1 (reference) & $\ldots$ & $\ldots$ & $\ldots$ \\
\hline$\geq 295.0$ & $20.342(7.235-57.192)$ & $<0.001^{* * *}$ & $11.867(2.569-54.815)$ & $0.002^{* *}$ & 2.474 & 25 \\
\hline \multicolumn{7}{|l|}{ Albumin (g/L) } \\
\hline$\geq 28.5$ & 1 (reference) & $\ldots$ & $\ldots$ & $\ldots$ & $\ldots$ & $\ldots$ \\
\hline$<28.5$ & $5.181(2.222-12.081)$ & $<0.001^{* * *}$ & $\ldots$ & $\ldots$ & $\ldots$ & $\ldots$ \\
\hline \multicolumn{7}{|l|}{ Creatinine $(\mu \mathrm{mol} / \mathrm{L})$} \\
\hline$<88.0$ & 1 (reference) & & $\ldots$ & $\ldots$ & $\ldots$ & $\ldots$ \\
\hline$\geq 88.0$ & $6.254(6.254-14.693)$ & $<0.001^{* * *}$ & $\ldots$ & $\ldots$ & $\ldots$ & $\ldots$ \\
\hline \multicolumn{7}{|l|}{ BUN (mmol/L) } \\
\hline$\leq 5.12$ & 1 (reference) & $\ldots$ & 1 (reference) & $\ldots$ & $\ldots$ & $\ldots$ \\
\hline$>5.12$ & $8.514(3.729-19.439)$ & $<0.001^{* * *}$ & $4.706(1.160-19.098)$ & $0.030^{*}$ & 1.549 & 15 \\
\hline \multicolumn{7}{|l|}{ CK-MB (ng/mL) } \\
\hline$\leq 0.70$ & 1 (reference) & $\ldots$ & $\ldots$ & $\ldots$ & $\ldots$ & $\ldots$ \\
\hline$>0.70$ & $9.889(4.173-23.434)$ & $<0.001^{* * *}$ & $\ldots$ & $\ldots$ & $\ldots$ & $\ldots$ \\
\hline \multicolumn{7}{|l|}{ Troponin I (ng/L) } \\
\hline$\leq 4.70$ & 1 (reference) & $\ldots$ & $\ldots$ & $\ldots$ & $\ldots$ & $\ldots$ \\
\hline$>4.70$ & $12.800(4.625-35.421)$ & $<0.001^{* * *}$ & $\ldots$ & $\ldots$ & $\ldots$ & $\ldots$ \\
\hline \multicolumn{7}{|l|}{ Prothrombin time (s) } \\
\hline$\leq 14.20$ & 1 (reference) & & $\ldots$ & $\ldots$ & $\ldots$ & $\ldots$ \\
\hline$>14.20$ & $3.140(1.374-1.374)$ & $0.007^{* *}$ & $\ldots$ & $\ldots$ & $\ldots$ & $\ldots$ \\
\hline D-Dimer ( $\mu \mathrm{g} / \mathrm{ml})$ & & & & & & \\
\hline
\end{tabular}


Table 3 Risk factors for developing ARDS among hospitalized COVID-19 patients (Continued)

\begin{tabular}{|c|c|c|c|c|c|c|}
\hline Variables & Univariable OR $(95 \% \mathrm{Cl})$ & $P$ value & Multivariable OR $(95 \% \mathrm{Cl})$ & $P$ value & $\beta$ coefficients & Assigned risk score \\
\hline$<5.00$ & 1(reference) & $\ldots$ & 1 (reference) & $\ldots$ & $\ldots$ & $\ldots$ \\
\hline$\geq 5.00$ & $35.000(7.445-164.531)$ & $<0.001^{* * *}$ & $30.001(2.282-394.374)$ & $0.010^{*}$ & 3.401 & 34 \\
\hline \multicolumn{7}{|c|}{ C-Reactive protein (mg/L) } \\
\hline$<38.00$ & 1 (reference) & $\ldots$ & $\ldots$ & $\ldots$ & $\ldots$ & \\
\hline$\geq 38.00$ & 22.398 (7.930-63.267) & $<0.001^{* * *}$ & $\ldots$ & $\ldots$ & $\ldots$ & $\ldots$ \\
\hline \multicolumn{7}{|l|}{$\operatorname{ESR}(\mathrm{mm} / \mathrm{h})$} \\
\hline$<60.0$ & 1 (reference) & $\ldots$ & $\ldots$ & $\ldots$ & $\ldots$ & $\ldots$ \\
\hline$\geq 60.0$ & $3.162(1.470-6.806)$ & $0.003^{* *}$ & $\ldots$ & $\ldots$ & $\ldots$ & $\ldots$ \\
\hline \multicolumn{7}{|c|}{ Procalcitonin (ng/ml) } \\
\hline$\leq 0.11$ & 1 (reference) & $\ldots$ & 1 (reference) & $\ldots$ & $\ldots$ & $\ldots$ \\
\hline$>0.11$ & $16.422(6.214-43.402)$ & $<0.001^{* * *}$ & 7.295 (1.772-30.042) & $0.006^{* *}$ & 1.987 & 20 \\
\hline \multicolumn{7}{|c|}{ Ferritin (ng/ml) } \\
\hline$<950.00$ & 1(reference) & $\ldots$ & 1 (reference) & $\ldots$ & $\ldots$ & $\ldots$ \\
\hline$\geq 950.00$ & $22.292(8.661-57.377)$ & $<0.001^{* * *}$ & $11.227(2.904-43.400)$ & $0.001^{* *}$ & 2.4184 & 24 \\
\hline
\end{tabular}

${ }^{*} p$-value $<0.05$

$* * p$-value $<0.01$

${ }^{* * *} p$-value $<0.001$

emphasize the preservation of renal function in patients with COVID-19, which plays a decisive role in fluid control for treatment of patients with ARDS [27]. With respect to the specific scores assigned to the individual risk factors, these variables may divided into groups with

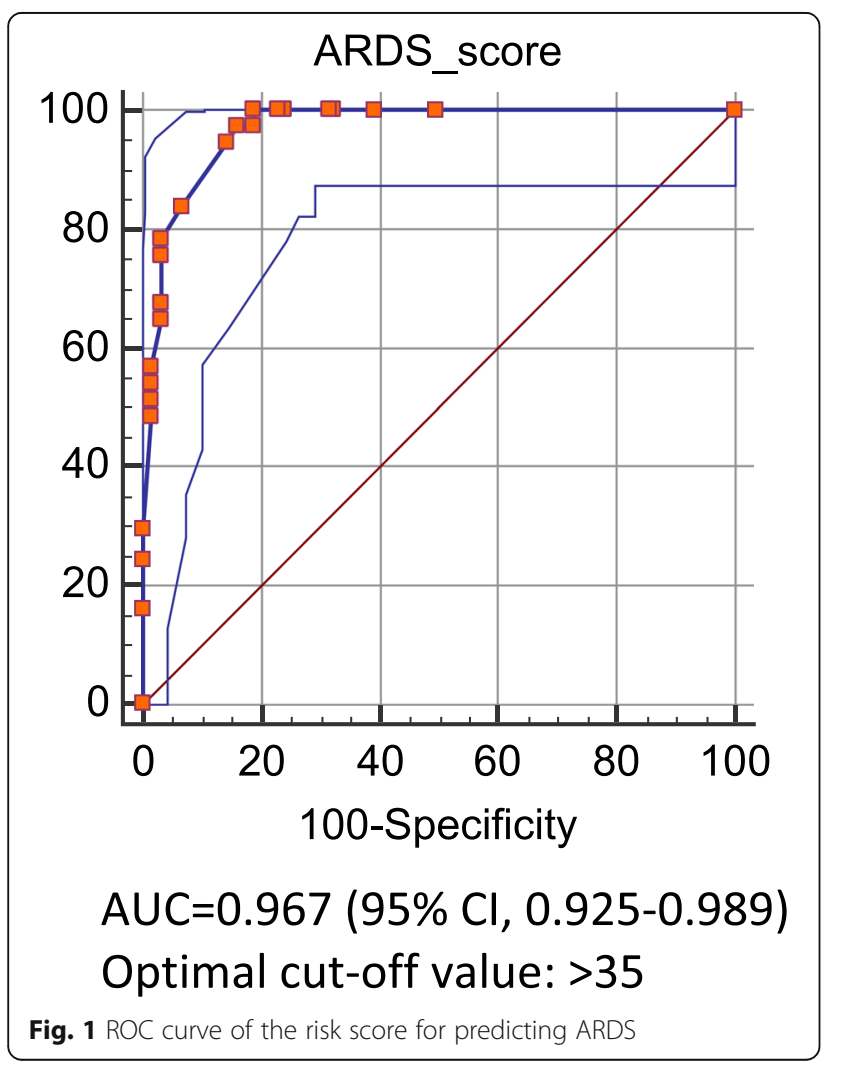

high scores, including those of LDH, D-dimer, and ferritin levels, with scores of 25,34, and 24, respectively, and groups with low scores, including those of BUN and PCT, with scores of 15 and 20, respectively. As the optimal cutoff value is $>35$, a positive result for any single factor is not sufficient to identify high-risk patients, and any combination of the three factors is sufficient. However, when evaluation is based on two variables, one should be included in the high-score group.

This study had several strengths. First, Wuhan Union Hospital is one of the first designated institutions for treating patients with COVID-19 in Wuhan. Thus, the participants constituted a representative sample of hospitalized patients. Moreover, this study had one of the largest populations with definite outcomes during hospitalization, thereby providing a strong evidence for depicting the risk factors of ARDS among patients with COVID-19. By contrast, after a systemic selection of possible risk factors, a panel of indices routinely tested in clinical settings were selected, and a risk evaluation score was designed with a relatively good predictive efficacy for practical use. However, this study also had several limitations. First, the interpretation of the results may be limited by the relatively small sample size.

Table 4 Evaluation of ARDS risk assessment model

\begin{tabular}{llll}
\hline $\begin{array}{llll}\text { Predicating } \\
\text { model }\end{array}$ & \multicolumn{2}{l}{ Berlin definition of ARDS } & Total \\
\cline { 2 - 3 } & ARDS & Non-ARDS & \\
\hline High risk & 10 & 11 & 21 \\
Low risk & 4 & 41 & 45 \\
Total & 14 & 52 & 66 \\
\hline
\end{tabular}


Second, studies involving external verification must be conducted to validate the efficacy of our model in predicting ARDS. Finally, Due to the heavy clinical work during the epidemic, some important indicators such as $\mathrm{PaO} 2$ and $\mathrm{PaO} 2 / \mathrm{FiO} 2$ have not been recorded in time, so these indicators cannot be included in our research.

\section{Conclusions}

Several variables were found to be differentially distributed between COVID-19 patients with and without ARDS. A rough stepwise selection method and a panel of risk factors, including LDH, BUN, D-dimer, PCT, and ferritin levels, were included in the prediction model, and a risk evaluation scoring system was established, with an optimal cutoff value $>35$ and AUC of 0.967 (95\% CI: 0.925-0.989). Moreover, the model had excellent discrimination and calibration during the internal validation, which is considered practical for clinicians. The novel risk scoring system may be a valuable tool for screening COVID-19 patients with a high risk of ARDS.

\section{Supplementary Information}

The online version contains supplementary material available at https://doi. org/10.1186/s12879-020-05561-y

Additional file 1: Table S1. Predictive efficiency of the ARDS risk score among hospitalized COVID-19 patients.

Additional file 2: Figure S1. ROC curves of individual risk factors for predicting ARDS.

\section{Abbreviations \\ COVID-19: Coronavirus disease 2019; ARDS: Acute respiratory distress syndrome; ROC curve: Receiver operating characteristic curve; AUC: Area under the curve; LDH: Lactate dehydrogenase; BUN: Blood urea nitrogen; PCT: Procalcitonin; SARS-CoV-2: Severe acute respiratory syndrome coronavirus 2; RT-PCR: Reverse transcription-polymerase chain reaction; C- reactive protein; CRP: Erythrocyte sedimentation rate; ESR: PaO2Partial pressure of atrial oxygen; FiO2: Fraction of inspired oxygen; PEEP: Positive end-expiratory pressure; CPAP: Continuous positive airway pressure; IQR: Interquartile range; Cl: Confidence interval; OR: Odds ratio}

\section{Acknowledgements}

Not Applicable.

\section{Authors' contributions}

JZ took responsibility for the design of the work. YM and ML took responsibility for drafting the manuscript. ML, MH, JT and XH took responsibility for data acquisition and analysis. ZL, SF, PC, HL, TB and YX participated in collecting data and interpreting the results. TB had substantively revised this work. The author(s) read and approved the final manuscript.

\section{Funding}

This work was supported by grant from Huazhong University of Science and Technology (HUST COVID- 19 Rapid Response Call, 2020kfyXGYJ009).

\section{Availability of data and materials}

All Data and material collected during this study are available from the corresponding author upon reasonable request. Wuhan Union Hospital was as one of the first hospital received patients with COVID-19 in Wuhan, so the data of some patients in this study was likely to be used in other studies.

\section{Ethics approval and consent to participate}

This study was approved by the Research Ethics Commission of Wuhan UnionHospital (KY-2020-0040), and the requirement for informed consent was waived by the Ethics Commission.

Consent for publication

Not Applicable.

\section{Competing interests}

The authors declared no competing interests.

\section{Author details}

'Department of Respiratory and Critical Care Medicine, Union Hospital, Tongji Medical Collage, Huazhong University of Science and Technology, 1277 Jiefang Avenue, Wuhan 430022, Hubei Province, China. ${ }^{2}$ Department of Neurology, Union Hospital, Tongji Medical Collage, Huazhong University of Science and Technology, 1277 Jiefang Avenue, Wuhan 430022, Hubei Province, China. ${ }^{3}$ Department of Gastroenterology, Union Hospital, Tongji Medical Collage, Huazhong University of Science and Technology, 1277 Jiefang Avenue, Wuhan 430022, Hubei Province, China.

Received: 13 June 2020 Accepted: 30 October 2020

Published online: 17 December 2020

\section{References}

1. Phelan AL, Katz R, Gostin LO. The novel coronavirus originating in Wuhan, China: challenges for Global Health Governance. JAMA. 2020;323(8):709-10.

2. Kickbusch I, Leung G. Response to the emerging novel coronavirus outbreak. BMJ. 2020;368:m406.

3. Wu Y, Ho W, Huang Y, Jin DY, Li S, Liu SL, et al. SARS-CoV-2 is an appropriate name for the new coronavirus. Lancet. 2020;395(10228):949-50.

4. Lu R, Zhao X, Li J, Niu P, Yang B, Wu H, et al. Genomic characterisation and epidemiology of 2019 novel coronavirus: implications for virus origins and receptor binding. Lancet. 2020;395(10224):565-74.

5. Xu Z, Li S, Tian S, Li H, Kong LQ. Full spectrum of COVID-19 severity still being depicted. Lancet. 2020;395(10228):947-8.

6. The Lancet. COVID-19: fighting panic with information. Lancet. 2020; 395(10224):537.

7. Wu Z, McGoogan JM. Characteristics of and important lessons from the coronavirus disease 2019 (COVID-19) outbreak in China: summary of a report of 72314 cases from the Chinese Center for Disease Control and Prevention. JAMA. 2020;323(13):1239-42.

8. Fan E, Brodie D, Slutsky AS. Acute respiratory distress syndrome: advances in diagnosis and treatment. JAMA. 2018;319(7):698-710.

9. Ranieri VM, Rubenfeld GD, Thompson BT, Ferguson ND, Caldwell E, Fan E, et al. Acute respiratory distress syndrome: the Berlin definition. JAMA. 2012; 307(23):2526-33

10. Yang $X, Y u$ Y, Xu J, Shu H, Xia J, Liu H, et al. Clinical course and outcomes of critically ill patients with SARS-CoV-2 pneumonia in Wuhan, China: a singlecentered, retrospective, observational study. Lancet Respir Med. 2020;8(5): $475-81$.

11. Thompson BT, Chambers RC, Liu KD. Acute respiratory distress syndrome. N Engl J Med. 2017;377(6):562-72.

12. Chen N, Zhou M, Dong X, Qu J, Gong F, Han Y, et al. Epidemiological and clinical characteristics of 99 cases of 2019 novel coronavirus pneumonia in Wuhan, China: a descriptive study. Lancet. 2020;395(10223):507-13.

13. Wang D, Hu B, Hu C, Zhu F, Liu X, Zhang J, Wang B, Xiang H, Cheng Z, Xiong Y, Zhao Y, Li Y, Wang X, Peng Z. Clinical characteristics of 138 hospitalized patients with 2019 novel coronavirus-infected pneumonia in Wuhan, China. JAMA. 2020;323(11):1061-9.

14. Huang C, Wang Y, Li X, Ren L, Zhao J, Hu Y, et al. Clinical features of patients infected with 2019 novel coronavirus in Wuhan, China. Lancet. 2020:395(10223):497-506.

15. Mosley JD, Gupta DK, Tan J, Yao J, Wells QS, Shaffer CM, et al. Predictive accuracy of a polygenic risk score compared with a clinical risk score for incident coronary heart disease. JAMA. 2020;323(7):627-35.

16. erg DD, Wiviott SD, Scirica BM, Gurmu Y, Mosenzon O, Murphy SA, et al. Heart failure risk stratification and efficacy of sodium-glucose Cotransporter2 inhibitors in patients with type 2 diabetes mellitus. Circulation. 2019; 140(19):1569-77. 
17. Abdul-Rahim AH, Perez AC, Fulton RL, Jhund PS, Latini R, Tognoni G, et al. Risk of stroke in chronic heart failure patients without atrial fibrillation: analysis of the controlled Rosuvastatin in multinational trial heart failure (CORONA) and the Gruppo Italiano per lo studio della Sopravvivenza nell'Insufficienza Cardiaca-heart failure (GISSI-HF) trials. Circulation. 2015; 131(17):1486-94 discussion 1494.

18. National Health Commission of the People's Republic of China. Chinese management guideline for COVID-19 (version 6.0). 2020. http://www.nhc. gov.cn/jkj/s3577/202003/4856d5b0458141fa9f376853224d41d7/files/4132bf0 35bc242478a6eaf157eb0d979.pdf.

19. Yao XH, Li TY, He ZC, Ping YF, Liu HW, Yu SC, et al. A pathological report of three COVID-19 cases by minimal invasive autopsies. Zhonghua Bing Li Xue ZA Zhi. 2020;49(5):411-7.

20. Xu Z, Shi L, Wang Y, Zhang J, Huang L, Zhang C, et al. Pathological findings of COVID-19 associated with acute respiratory distress syndrome. Lancet Respir Med. 2020;8(4):420-2.

21. Williams MJ, Poulton R, Williams S. Relationship of serum ferritin with cardiovascular risk factors and inflammation in young men and women. Atherosclerosis. 2002;165(1):179-84.

22. Vanarsa K, Ye Y, Han J, Xie C, Mohan C, Wu T. Inflammation associated anemia and ferritin as disease markers in SLE. Arthritis Res Ther. 2012;14(4): R182.

23. Sharkey RA, Donnelly SC, Connelly KG, Robertson CE, Haslett C, Repine JE. Initial serum ferritin levels in patients with multiple trauma and the subsequent development of acute respiratory distress syndrome. Am J Respir Crit Care Med. 1999;159(5 Pt 1):1506-9.

24. $X u X W, W u X X$, Jiang $X G, X u K J$, Ying $L$, Ma $C L$, et al. Clinical findings in a group of patients infected with the 2019 novel coronavirus (SARS-Cov-2) outside of Wuhan, China: retrospective case series. BMJ. 2020;368:m606.

25. Zhou F, Yu T, Du R, Fan G, Liu Y, Liu Z, et al. Clinical course and risk factors for mortality of adult inpatients with COVID-19 in Wuhan, China: a retrospective cohort study. Lancet. 2020;395(10229):1054-62.

26. Connelly KG, Moss M, Parsons PE, Moore EE, Moore FA, Giclas PC, et al. Serum ferritin as a predictor of the acute respiratory distress syndrome. Am J Respir Crit Care Med. 1997;155(1):21-5.

27. Matthay MA, Zemans RL, Zimmerman GA, Arabi YM, Beitler JR, Mercat A, et al. Acute respiratory distress syndrome. Nat Rev Dis Primers. 2019;5(1):18.

28. Herridge MS. Fifty years of research in ARDS. Long-term follow-up after acute respiratory distress syndrome. Insights for managing medical complexity after critical illness. Am J Respir Crit Care Med. 2017;196(11): 1380-4.

29. Giamarellos-Bourboulis EJ, Mega A, Grecka P, Scarpa N, Koratzanis G, Thomopoulos G, et al. Procalcitonin: a marker to clearly differentiate systemic inflammatory response syndrome and sepsis in the critically ill patient? Intensive Care Med. 2002;28(9):1351-6.

30. De Freitas CN, Gaudet A, Portier L, Tsicopoulos A, Mathieu D, Lassalle P. Endocan, sepsis, pneumonia, and acute respiratory distress syndrome. Crit Care. 2018;22(1):280

31. Shen Z, Xiao Y, Kang L, Ma W, Shi L, Zhang L, et al. Genomic diversity of severe acute respiratory syndrome-coronavirus 2 in patients with coronavirus disease 2019. Clin Infect Dis. 2020;71(15):713-20.

32. Rothan HA, Byrareddy SN. The epidemiology and pathogenesis of coronavirus disease (COVID-19) outbreak. J Autoimmun. 2020;109:102433.

33. Lin L, Lu L, Cao W, Li T. Hypothesis for potential pathogenesis of SARS-CoV2 infection-a review of immune changes in patients with viral pneumonia. Emerg Microbes Infect. 2020;9(1):727-32.

34. Mulier B, Rahman I, Watchorn T, Donaldson K, MacNee W, Jeffery PK. Hydrogen peroxide-induced epithelial injury: the protective role of intracellular nonprotein thiols (NPSH). Eur Respir J. 1998;11(2):384-91.

35. Ríos FG, Estenssoro E, Villarejo F, Valentini R, Aguilar L, Pezzola D, et al. Lung function and organ dysfunctions in 178 patients requiring mechanical ventilation during the 2009 influenza a (H1N1) pandemic. Crit Care. 2011; 15(4):R201.

36. Mezquita L, Auclin E, Ferrara R, Charrier M, Remon J, Planchard D, et al. Association of the Lung Immune Prognostic Index with Immune Checkpoint Inhibitor Outcomes in patients with advanced non-small cell lung Cancer. JAMA Oncol. 2018;4(3):351-7.

37. Ding J, Karp JE, Emadi A. Elevated lactate dehydrogenase (LDH) can be a marker of immune suppression in cancer: interplay between hematologic and solid neoplastic clones and their microenvironments. Cancer Biomark. 2017;19(4):353-63.
38. Simmons WK. Urinary urea nitrogen-creatinine ratio as indicator of recent protein intake in field studies. Am J Clin Nutr. 1972;25(5):539-42.

\section{Publisher's Note}

Springer Nature remains neutral with regard to jurisdictional claims in published maps and institutional affiliations.
Ready to submit your research? Choose BMC and benefit from:

- fast, convenient online submission

- thorough peer review by experienced researchers in your field

- rapid publication on acceptance

- support for research data, including large and complex data types

- gold Open Access which fosters wider collaboration and increased citations

- maximum visibility for your research: over $100 \mathrm{M}$ website views per year

At BMC, research is always in progress.

Learn more biomedcentral.com/submissions 